\title{
The Ride-Sharing Services in Bangladesh: Current Status, Prospects, and Challenges
}

\author{
Md. Nazmus Sakib* Md. Hasan Mia \\ Department of Management (MBA in SIM), University of Dhaka, Bangladesh
}

\begin{abstract}
The study reveals the current status, prospects, and challenges of ride-sharing services in Bangladesh. The current status and prospects are analyzed from the viewpoint of customers and users with a sample of 200 and the challenges have been traced from the business perspective with a sample of 10 executives of different ride-sharing organizations. There are 177 and 8 respondents from the sample of 200 and 10 respectively. It has gained an immense acceptance among the young generations and businesses due to its distinct prospects, for instance, realtime response, more convenient, on-demand location, user-friendliness, and so on. The major challenges have been identified as fund shortage, lack of logistic support, lack of awareness, adverse government policies, intense competition and so forth.
\end{abstract}

Keywords: Ride-sharing services, prospects, challenges, Bangladesh.

DOI: $10.7176 / \mathrm{EJBM} / 11-31-05$

Publication date: November $30^{\text {th }} 2019$

\section{Introduction}

In developing countries like Bangladesh, one of the key indicators for economic development is the advancement of transportation and communication system and ride-sharing is one of them. Hence, the wide array of onlinebased service industries such as app-based ride-sharing, travel tickets, online procurement, etc. are in a boom which reduces the amount of effort needed, time, and cost of mobility from one place to another (Tang and Wang, et at., 2017).

The ride-sharing services have an immense role in case of social, economic, sustainability and environmental issues by reduction traffic jams, making minimum number of vehicles on the road (Hansan et al., 2010). Due to the availability of smartphones and wide access to the internet, different app-based services have increased drastically as it is helpful to identify the nearest vehicles within the shortest possible time. Apart from this, it facilitates to easily track driver's location, expected destination, and computerized fixation of fares virtually on screen by mobile app (Chen et al., 2011).

The ride-sharing services have got a lion share acceptability in the developed as well as developing countries especially, among young generations, investors, business persons, government officials and so on. As it reduces the hassle of maintaining private transportation vehicles tremendously and removes the tiresome, boredom and harassment of public transportation (Amey, Attanucci, and Mishalani, 2011). As such, from the user's perspective, it is the most convenient and friendly mode of transportation which is more time saving and cost-efficient than those of traditional transportation. From the business perspective, it raises and untapped opportunities to capture the potential market, increasing market share and social benefits such as the creation of employment, reducing traffic jams which subsequently generate a major source of revenues (Tang and Wang, et at., 2017).

Following the trends, firstly the Uber has started operation in Bangladesh app-based ride-sharing services and enjoyed the first-mover advantages with wide array of popularity. Subsequently, Pathao successfully has launched app-based services and being followed by other companies such as Jobike, Obhai, Obon, Amarbike, Texiwala, Gariwala, Sohoz-ride, Chalu, and others. Within very short period of time they have been able to win the popularity of general people as cost-saving, real-time response and on-demand transport facilities. The vast prospects arise having a wide scope of acceptability and opportunities to grab and unveil a new business arena.

Since a few studies have been conducted on ride-sharing services as new business platform in case of least developed countries like Bangladesh, the study is undertaken to identify the current status of ride-sharing services from user perspective along with the challenges from a business perspective.

The paper is arranged into seven different chapters including introduction. Reviewing literature of relevant theories, concepts, prospects, model and challenges of ride-sharing services and objectives of this research have been organized in chapters two and three consecutively. Chapter four highlights the methodology of this research. In chapter five, detailed analysis and significant findings along with a general discussion on demographic profile of sample, current status, prospects, and challenges of ride-sharing services in Bangladesh have been offered. Chapter six focuses a proposed model by covering the entire paper and finally, conclusion and recommendations are followed in chapter seven.

\section{Literature Review and Background}

The transportation and communication system across the universe have got radical changes nowadays. By the 
introduction and practice of the concept of the global village, the world is transforming into the area virtually reachable to all the people from far and near within the shortest possible time. The ever-growing wave of global communication systems and technologies has also started to flow freely in developing countries like Bangladesh. The best use of advanced technology and the internet are closely reciprocal to each other (Giannopoulos, 2004).

With the rapid industrialization and infrastructural development, the transportation and communication system has got radical changes by using modern technology such as advanced vehicles, mobile communication networks, real-time responses, standard bandwidth of internet, web 2.0 technology and service, etc. The comparative advantages in telecommunication, business, and transportation, is far above than the changes in any other sectors (Mohiuddin, 2014). The number of internet users has tripled over the last five (05) years. In 2013, internet users in Bangladesh were just $6.5 \%$. but in 2017 , this growth has reached up to $18.7 \%$ of the total population. The e-commerce market is estimated at about $\$ 110-115$ million (about 900 crores per year) in 2017 (Bangladesh Association of Software and Information Services, 2018). Furthermore, in the global ICT development index, Bangladesh has ranked 147 among 176 countries in the world (Debnath, \& Mahmud, 2007). Now the whole country, as well as the universe, is an online marketplace where the buyer can reach their desired products and services with just a click of a mouse. From the perspective of Bangladesh, in the case of the service sector, this is getting more popular with all classes of people (Hasan \& Huda, 2013).

Online-based businesses now are becoming more and more popular due to their worldwide acceptability, convenience, distance reach, for checking the products and prices with real-time responses and operations. The use of e-business tools and techniques has increased the rate of success in this regard (Lal, 2005). Furthermore, the ride-sharing app-based services have reduced the number of vehicles and traffic resulting save of production hour of the workforce (Giampapa, et, al. 2017). Ride-Sharing business has integrated the mobile phone internet and other social networking into the real-time service for the customers (Chan, N. D., \& Shaheen, S. A. 2012).

At present, the dynamic and online-based ride-sharing has brought together the service holders and the service provider at very short notice which is associated with lots of benefits such as reducing the burden of using excessive personal vehicles, maintenance, congestion, and cost. Moreover, this also fruitful in making new employment especially a part-time basis for the students and college-going mass (Agatz, et, al. 2012).

In recent times different ride-sharing business has paved the way to explore the opportunities and benefits based on internet and online marketing. The public transportation sector is very fragile where people suffer a lot (Andaleeb, Haq, and Ahmed, 2007). But the current scenario has been changed with the advancement of modern transportation technologies. Uber plays a positive role to create mammoth popularity among young generations and middle-aged which changes the transportation scenario in Bangladesh (Kumar, Jafarinaimi and Bin Morshed, 2018).

It is also observed only $4 \%$ of the private cars are actually used with an average of 50-60 rides per month but the rest of $96 \%$ is unused or kept idle. Hence, this scenario can be changed with the use of the ride-sharing business (The Financial Express, 2018). Moreover, in the case of Bangladesh where traffic-jam is a major problem, using the personal car will also acute the problem by increasing the number of vehicles in the street. According to world bank traffic eats up 3.2 million work hours per day in Dhaka (The World Bank, 2017). These vehicles require a huge amount of investment and maintenance cost which is a matter of concern in this case. To own, run and maintain a private car cost about BDT 70,000 per month in Bangladesh. So, these assets need additional focus to ensure the best utilization and use. In public transportation, there are not enough seats for people to accommodate according to demand. Ridesharing can serve larger masses than private cars do. It can be termed as 'Urban Solution' to reducing traffic jams (The Financial Express, 2018).

Ridesharing business is associated with intense competition and challenges in the market to compete and survive. Public transport like buses has economies of scale of carrying larger passengers at a minimal cost. Here ride-sharing business-facing difficulty to survive without intense care of the government. The information gap between the customers and the service provider is also high. Eventually, customers do not have sufficient information about the service, capacity, price, service provider, etc. (Amey, Attanucci, and Mishalani, 2011).

Due to the inefficiency of information, customers have little trust whether a driver has a criminal intention or record. Still, customers have doubts about the reliability of the service. This radically reduces the trust of customers as well as the market at large. Due to technological advancement, this type of business is evolved. In the near future, it also needs to be updated to cope with the changes in technology. To continue real-time services may not be possible with a limited, unskilled, and inefficient workforce in the perspective of developing countries (Amey, Attanucci, and Mishalani, 2011).

There is plenty of research which presents the business model of ride-sharing systems along with its prospects from the perspective of developed and developing countries. The previous research also focuses on the enormous potential to tap the opportunities of ride-hailing services in emergent economies. But so far as the concern of the researchers, there is no available research regarding the current status, prospects, and challenges of ride-hailing services in Bangladesh. So, the present study is intended to fill the gap. 


\section{Objectives of the Study}

General objective: The broad objective of the study is to identify the prospects and challenges of ride-sharing businesses in Bangladesh.

\section{Specific objectives:}

1. To assess existing ride ride-sharing businesses in Bangladesh.

2. To ascertain the prospects of ride-sharing businesses in Bangladesh.

3. To explore the challenges of ride-sharing businesses in Bangladesh.

4. To provide the appropriate suggestions for ride-sharing businesses in Bangladesh.

\section{Research Methodology}

The study is designed based on descriptive analysis. Both primary and secondary data have been used in this study. Secondary data is collected from different published sources such as books, journals, articles, reports, etc. On the other hand, the primary data has been collected from two sets of questionnaire surveys. On is approached to general people seeking the current status and prospects of ride-sharing services from the perspective of Bangladesh and the other is directed to different executives of ride-sharing companies to identify the challenges they are facing right now. To serve the purpose of collecting data by questionnaire survey, a total of 210 samples was waved through online utilizing a non-random convenience sampling method in which 200 were general customers and 10 were from executive and think tanks of these organizations. Among which 177 of general people out of 200 and 8 of executives out 10 from Uber, Pathao, Obhai, Obon, Amarbike, Texiwala, Gariwala, Sohoz Ride, Essyride, Chalu, shareamotorcycle.com, etc. have responded in this regard.

\section{Analysis and Findings}

This study is undertaken to identify the current status, and prospects of ride-sharing services from user perspective and challenges of the same from businesses' viewpoint.

\subsection{From the User Perspective}

5.1.1 Demographic profile: Among the 177 respondents, there are $66.1 \%$ male and $33.9 \%$ female in which $52.3 \%$ of respondents are aged below 30 and 39.2 of them ranged between $30-40$ years. Rest $8.5 \%$ of them are above 40 years. Most of the respondents are students representing $52.3 \%$ justifying that most of the users of ride-sharing services are young generation. Another $29.5 \%$ users are from business occupation and the rest of $18.2 \%$ are from other professions.

5.1.2 Current status and prospects of ride-sharing services: From a total of 177 respondents $76.80 \%$ are frequently using ridesharing services on an average two or three times a month. On the other hand, the rest of the $23.20 \%$ have never taken the ride-sharing services in their life which is indicating in the following figure:

\section{Have you ever taken ride-sharing services? \\ (177 responses)}

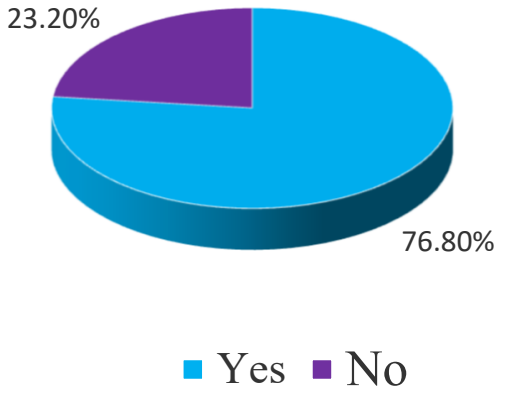

Figure 5.1: Percentage of the user and non-user of ride-sharing services.

Those who $(23.20 \%)$ are not using ride-sharing services in their life, they are persuaded by the following factors configured in the chart below. 


\section{If your answer is NO, then which factors persuade you not to using it?}

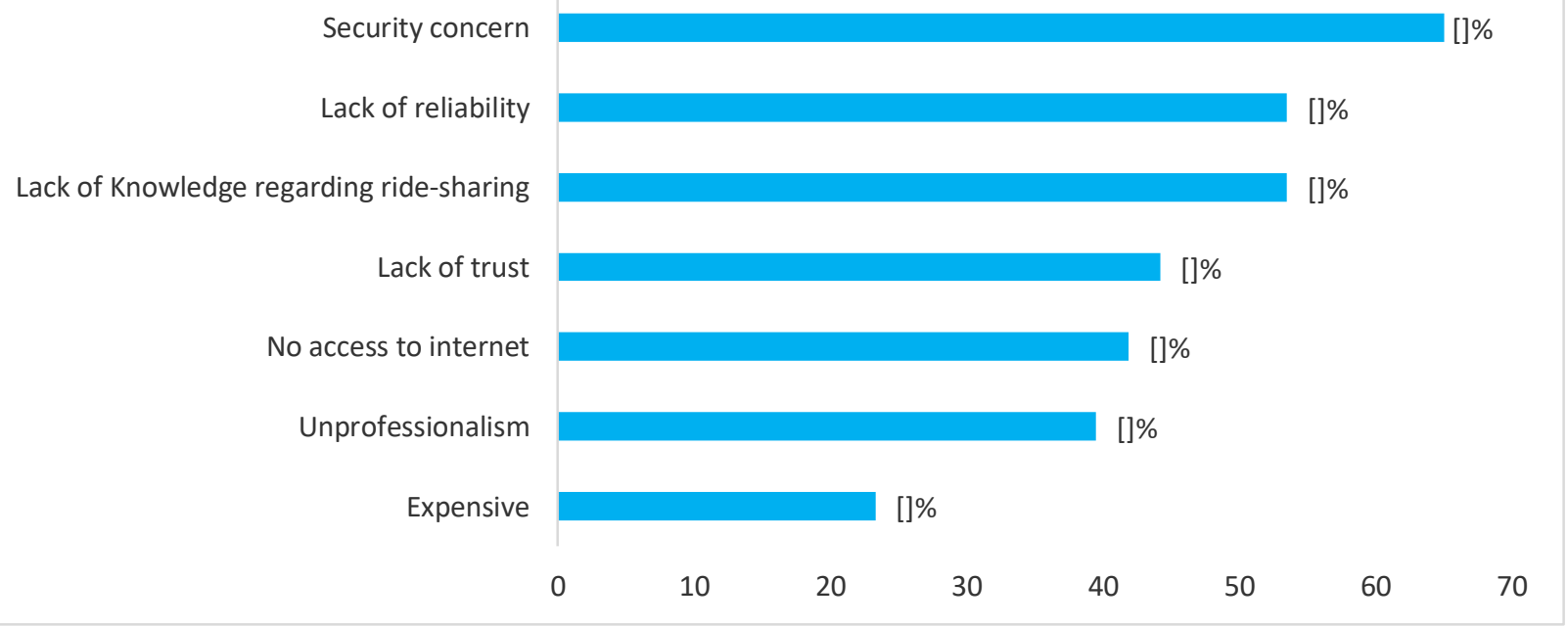

Figure 5.2: Factors persuading not to take ride-sharing services.

Among the seven factors, the non-users perceive that security and lack of reliability is the prime concern in this regard. Since the service inaugurating in Bangladesh, it has to go a long distance to win the trust and reliability of the common people. This also revealed that people have a lack of knowledge about the service and usage appropriately.

The respondent who are using the services, the following factors has immense influences.

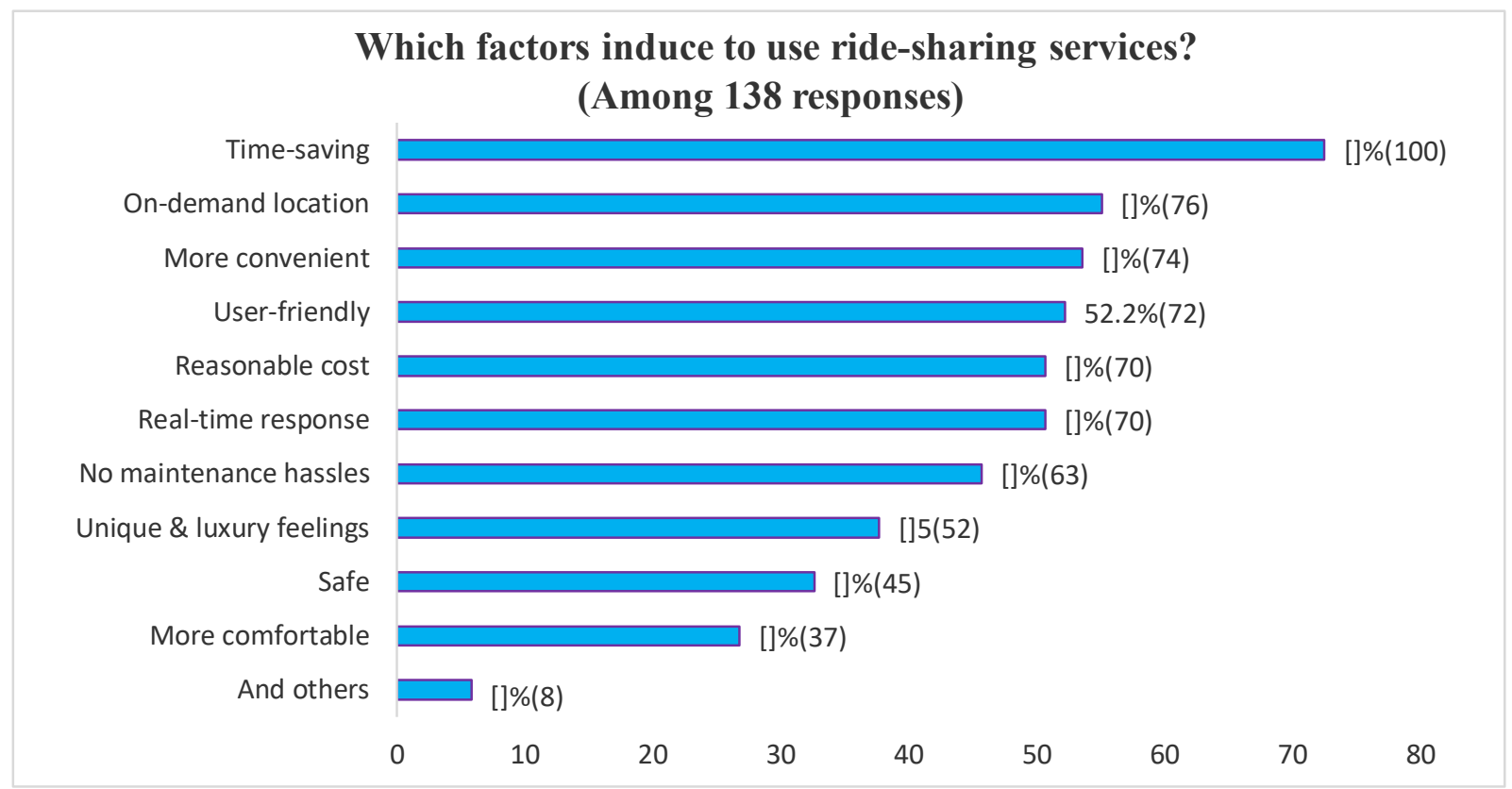

Figure 5.3: Factors Inducing to use ride-Sharing Services in Bangladesh

It is very much popular with the ng generation because of time-saving, convenient and on-demand location which is completely absent in the traditional transportation system. Since one needs to stand on the bus stand, rail station or port for their desired destination but ride-sharing usually picks from door to door of customer. Meanwhile, user-friendliness, real-time response, and no maintenance hassle also influence moderately to use it rapidly. The most popular service providers among the users are demonstrated in the following bar diagram. 


\section{The Service provider you have used often (143 responses)}

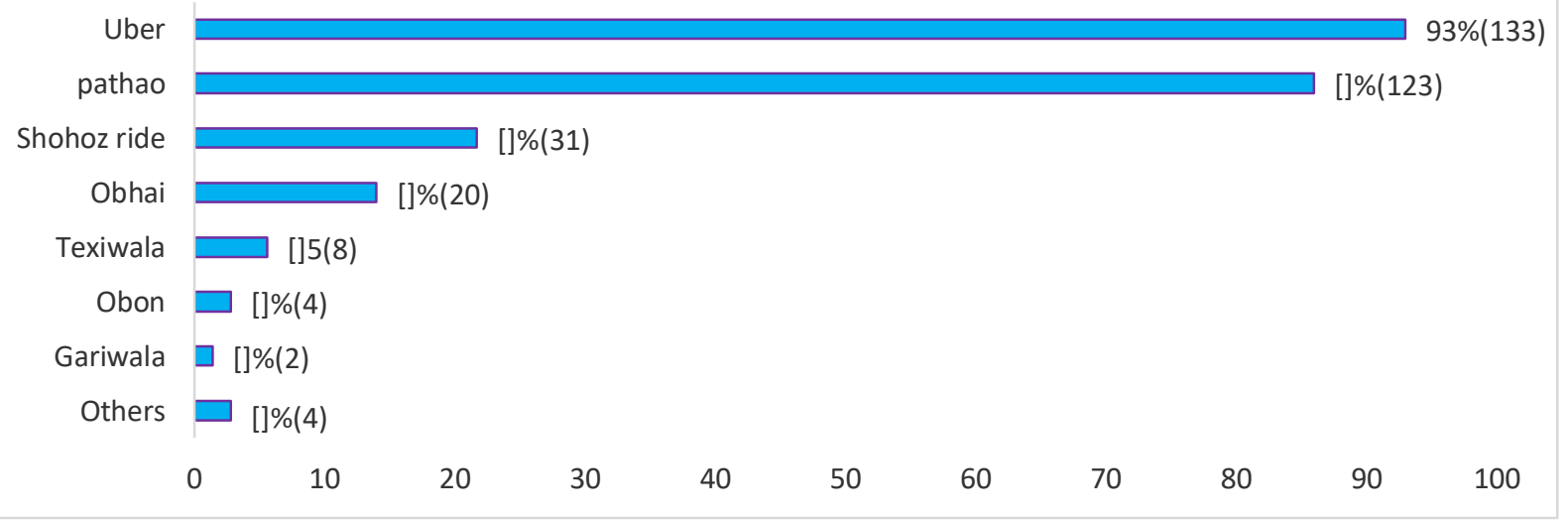

\section{Figure 5.4: The most popular ride-sharing service providers}

Since Uber is the first accessor in the market, most of the users take ride-sharing services from Uber. In this regard Uber is enjoying the first-mover advantages while Pathao faces intense competitions and obtained the second most commonly used vehicles after Uber. And the other service providers are trying to win the trust and gain wide customers' acceptance in the market.

The following diagram represents the problems and hassles in the case of using ride-sharing services.

\section{Troublesome and problem you usually faced using ride-sharing services} (140 responses)

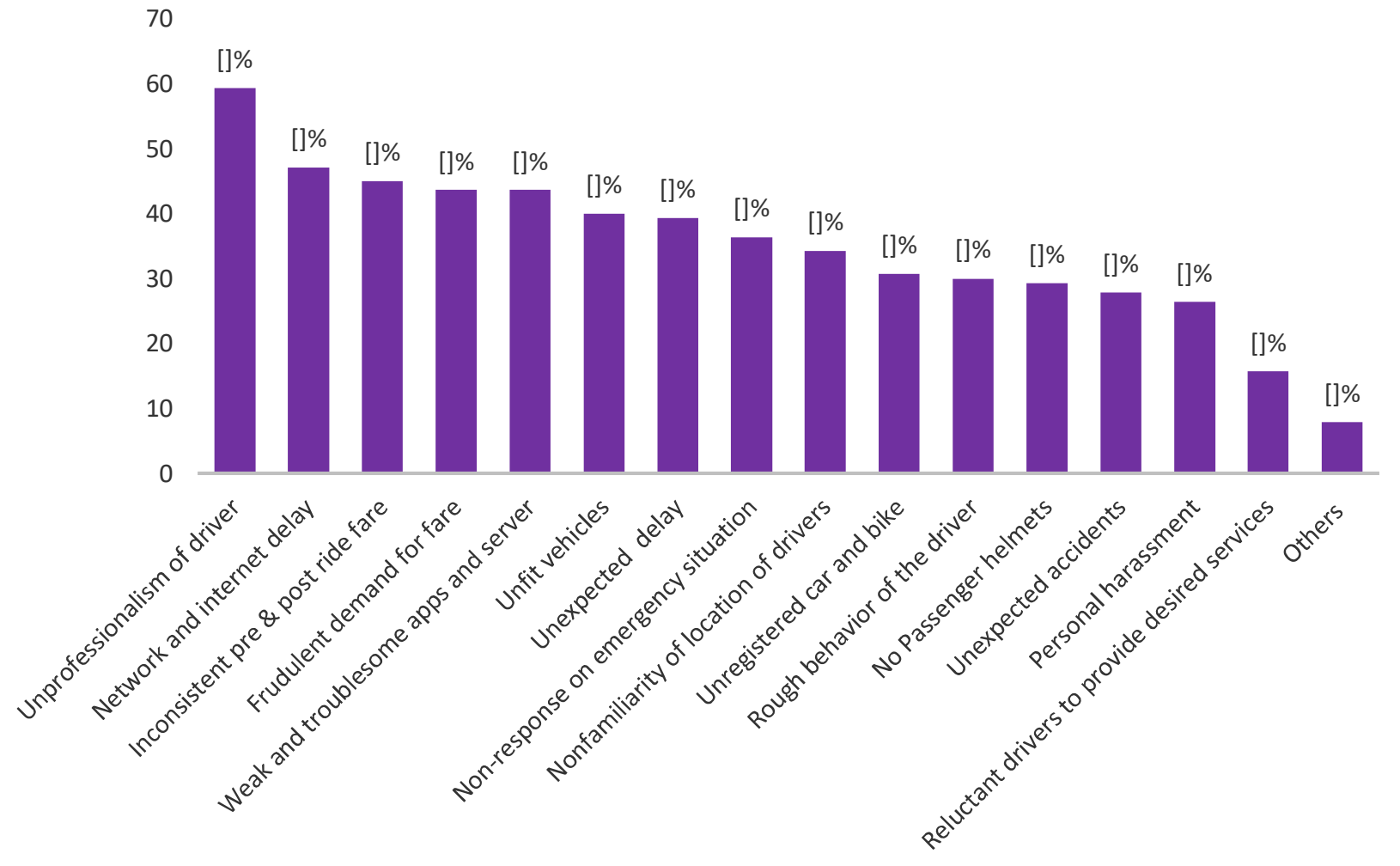

Figure 5.5: Problems and hassles in using ride-sharing services.

To trace the hassles and problems while taking ride-sharing services, are noticed as the unprofessionalism of the drivers, poor internet and network delay, inconsistency of pre and post-ride fare, poor and troublesome apps and servers are much more crucial to prevent a user or discourage to go for it. While the unfit vehicles, unexpected delay, and non-responses on emergency situations have made the service not up to the expectation. 
The users of ride-sharing services consider the following improvement should be bestowed with to add more values for better and quality services.

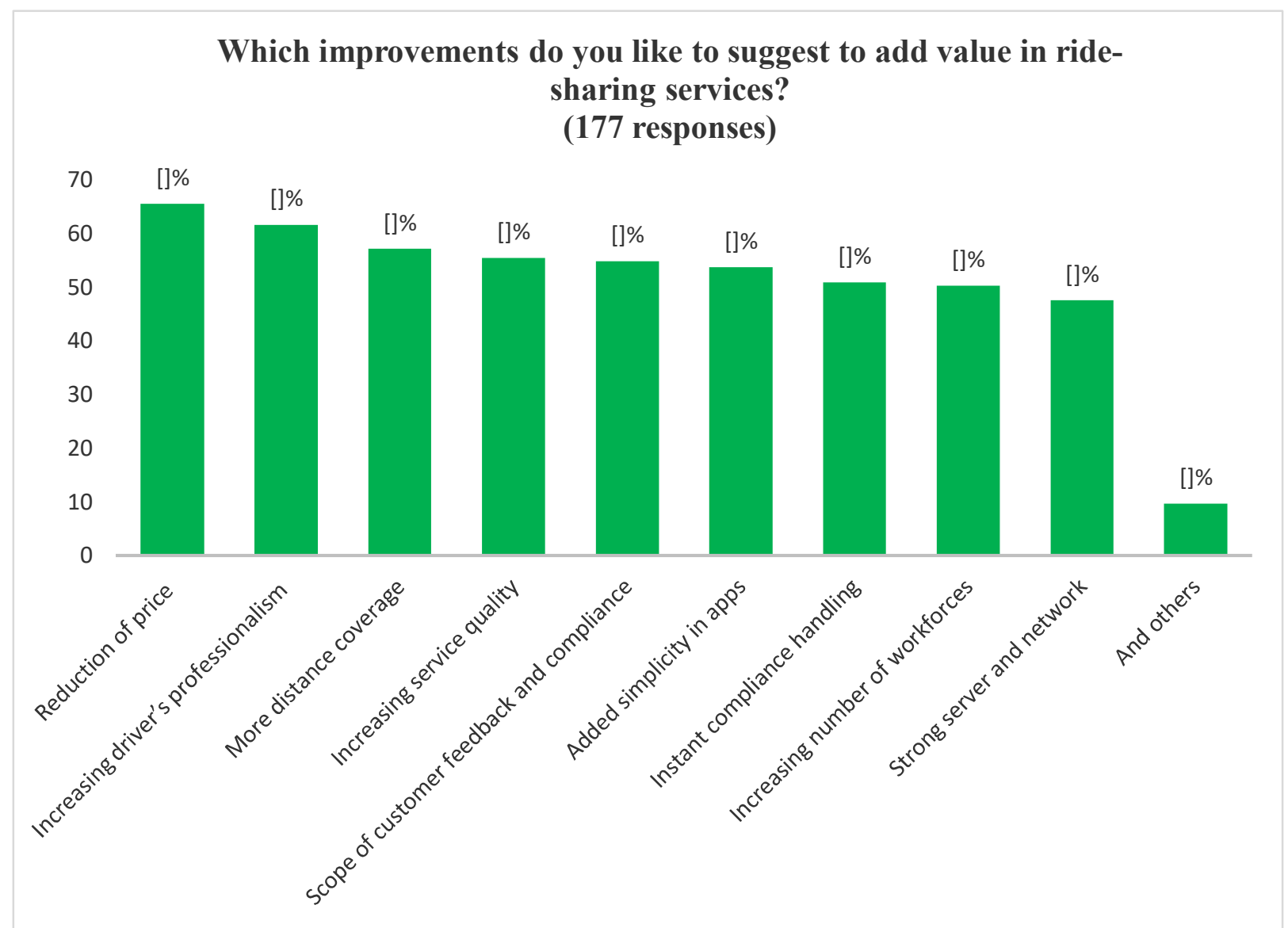

Figure 5.6: Improvement and suggestions for better services.

In contrast to the public transportation the ride-sharing services usually cots twice or thrice as such the users consider that the price should be reduced to make it more popular and affordable for all. Furthermore, the drivers need to be more professional, to quality, considering customer feedback and handling the compliance more effectively. The decision-maker should extend the service to other cities also. Additionally, the apps and servers need to be strengthened to cover and ensure quality services within short.

\subsection{From businesses perspective}

\subsubsection{Challenges of ride-sharing services:}

The following challenges are revealed from the viewpoint of decision-makers and executives of various ridesharing organizations including Uber, Pathao, Obhai, Obon, Amarbike, Texiwala, Gariwala, Sohoz Ride, Chalu, Shareamotorcycle.com, etc. 


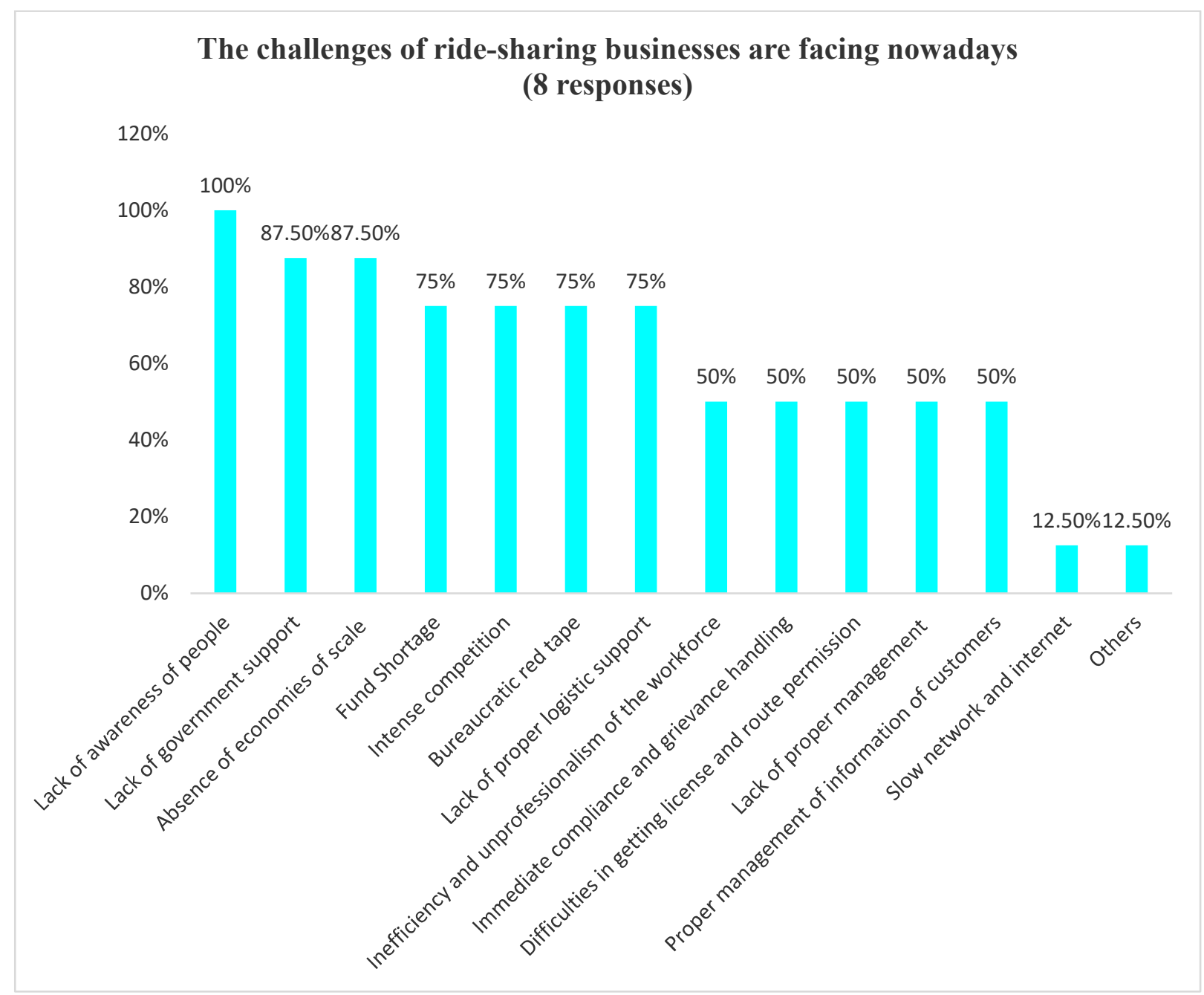

\section{Figure 5.7: Challenges of ride-sharing businesses}

Since Bangladesh is a developing country, the people are not very much aware and conscious about the use of latest technologies and technology-based services. Hence, the main challenges are to make the services well known, raise awareness and reached the major cities of the country. From the perspective of Bangladesh, the ridesharing companies can be considered as an infant sector absence of economies of scale, needs more care and support of the government to raise funds, infrastructure, and management. Furthermore, they face intense competition in market, having bureaucratic red tape, difficulties in getting license and route permit and lacking logistic support to start services in new cities or territory. Oppositely, unprofessionalism, inefficiency in management, failure in compliance handling have made the scenario more complex and complicated. Moreover, recently imposed a 5\% tax on ride-sharing services, has intensified the challenges. 


\section{Proposed Model}

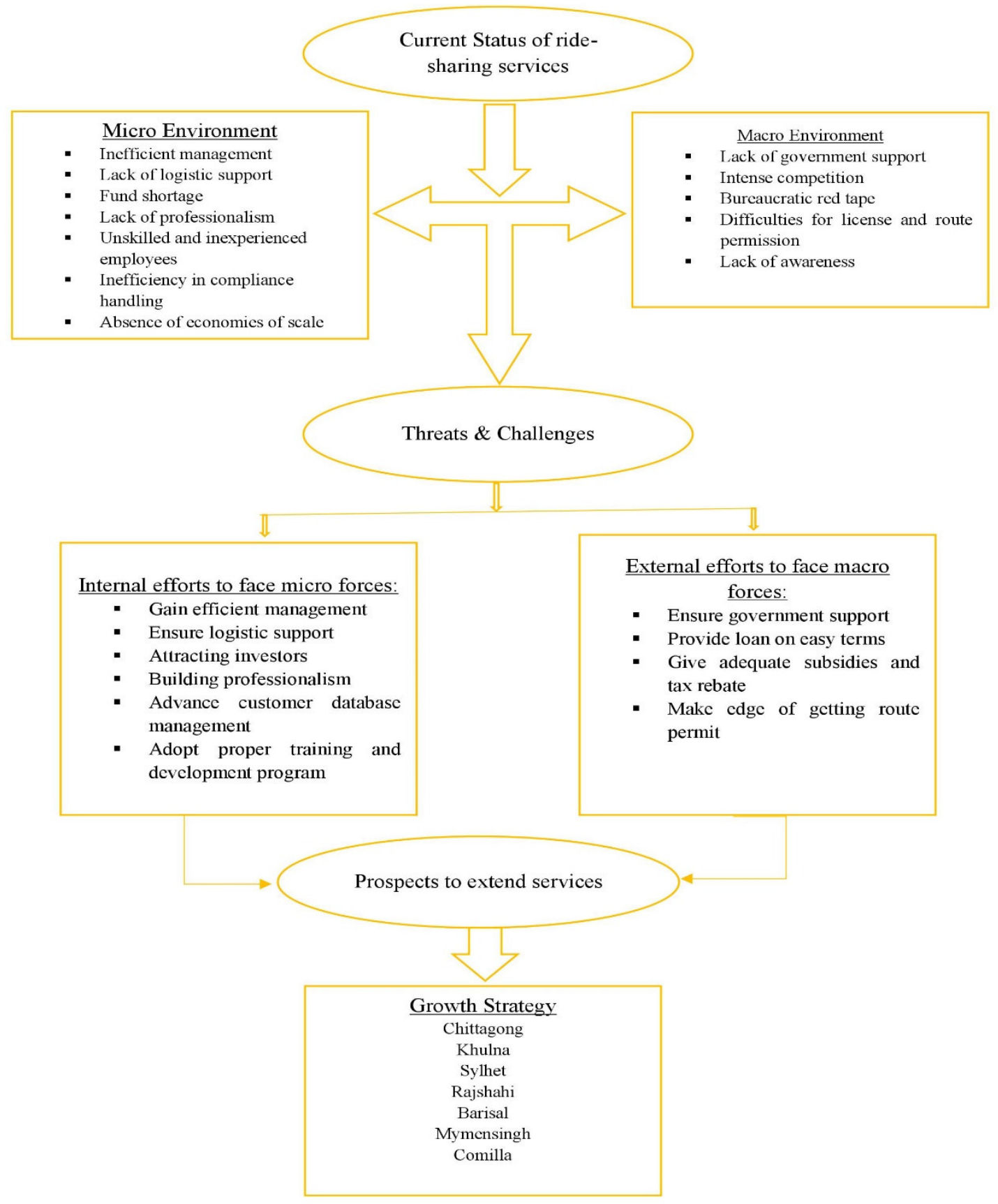

Source: Authors (2019)

\section{Conclusion and Recommendations}

The ride-sharing services have distinct prospects and challenges from the perspective of Bangladesh. Proper initiatives should be taken from the standpoint of executives as well as the law-making body to overcome the challenges and threats and utilize the prospects and opportunities so that this service can be reached to other cities successfully.

In order to improve the quality and services of the ride-sharing organization, the government can render crucial role-taking appropriate initiatives, i., e providing subsidies to save infant industries, providing logistics and infrastructural support, making edge on getting license and route permission, offering loan on easy terms and conditions. In addition, government can reconsider the 5\% levied tax, and offer tax rebates to overcome the challenges they are facing right now. The organization also required to strengthen the quality of apps and servers by extending and focusing the other cities within the shortest possible time. They also need to make effort to make awareness and reach their services to all potential customers by suitable promotion and advertisement in order to 
get known, acceptable and make the vendors understood the comparative advantages of taking this service.

\section{Avenues for Future Research}

The ride-sharing service is an infant business sector in developing countries like Bangladesh. People are showing more interest in ride-sharing services in Bangladesh. Further study can be undertaken how to expand the ridesharing services successfully in other cities than Dhaka by overcoming all the challenges and threats and at the same utilizing full potential of this business.

\section{References}

Agatz, N., Erera, A., Savelsbergh, M., \& Wang, X. (2012). Optimization for dynamic ride-sharing: A review. European Journal of Operational Research, 223(2), 295-303.

Amey, A., Attanucci, J., \& Mishalani, R. (2011). Real-time ridesharing: opportunities and challenges in using mobile phone technology to improve rideshare services. Transportation Research Record, 2217(1), 103-110.

Andaleeb, S. S., Haq, M., \& Ahmed, R. I. (2007). Reforming innercity bus transportation in a developing country: A passenger-driven model. Journal of Public Transportation, 10(1), 1- 26. https://doi.org/10.5038/23750901.10.1.1

Age. N (2019). Bangladesh e-commerce sector to grow to Tk 900cr this year: report. Retrieved 6 August 2019,fromhttp://www.newagebd.net/article/28655/bangladesh-e-commerce-sector-to- grow-to-tk-900crthis-year-report.

Chan, N. D., \& Shaheen, S. A. (2012). Ridesharing in North America: Past, present, and future. Transport Reviews, 32(1), 93-112.

Debnath, N. C., \& Mahmud, A. A. (2007). The Environment of E-commerce in Bangladesh.

Giampapa, et, al. (2017). Accessible Transportation Technologies Research Initiative (ATTRI).

Giannopoulos, G. A. (2004). The application of information and communication technologies in transport. European journal of operational research, 152(2), 302-320.

Hasan, M., \& Huda, M. N. (2013). E-commerce challenges, solutions and effectiveness perspective Bangladesh. International Journal of Computer Applications, 70(9).

Kumar, N., Nassim J., \& Bin Morshed, M. (2018). Uber in Bangladesh: The Tangled Web of Mobility and Justice. Proceedings of the ACM on Human-Computer Interaction 2 (November): 98. https://doi.org/10.1145/3274367

Lal, K. (2005). Determinants of the adoption of e-business technologies. Telematics and Informatics, 22(3), 181199.

Mohiuddin, M. (2014). Overview the e-commerce in Bangladesh. IOSR Journal of Business and Management, 16(7), 01-06.

The World Bank. (2017). A Modern Dhaka is Key to Bangladesh's Upper-Middle Income Country Vision. Retrieved 30 August 2019, from https:/www.worldbank.org/en/news/press- release/2017/07/19/moderndhaka-key-bangladesh-upper-middle-income-country-vision

Amey, A., Attanucci, J. and Mishalani, R., (2011). Real-time ridesharing: opportunities and challenges in using mobile phone technology to improve rideshare services. Transportation Research Record, 2217(1), pp.103110.

Yu, B., Ma, Y., Xue, M., Tang, B., Wang, B., Yan, J. and Wei, Y.M., (2017). Environmental benefits from ridesharing: A case of Beijing. Applied energy, 191, pp.141-152.

Hansen, E. G., Gomm, M. L., Bullinger, A. C., \& Moslein, K. M. (2010). A community-based toolkit for designing ride-sharing services: the case of a virtual network of ride access points in Germany. International Journal of Innovation and Sustainable Development, 5(1), 80-99. https://doi.org/10.1504/IJISD.2010.034559.

Chen, C. M., Shallcross, D., Shih, Y. C., Wu, Y. C., Kuo, S. P., Hsi, Y. Y., Holderby, Y., \& Chou, W. (2011). Smart ride share with flexible route matching. In Advanced Communication Technology ( ICACT), 2011, 13th International Conference on (pp. 1506-1510). IEEE.

Bangladesh Association of Software and Information Service (2018). IT and its industry overview.[online] Available at: https://basis.org.bd/publication/630704205a2084de27be4d5920540edf.pdf.

Express, F (2018). 'Uber-Pathao' ride-share's impact on Dhaka. [online] The Financial Express. Available at: https://thefinancialexpress.com.bd/views/uber-pathao-ride-shares-impact- on-dhaka-1524842540.

Md. Nazmus Sakib. Md. Nazmus Sakib is currently pursuing his Masters of Business Administration (MBA) degree in Strategic and International Management (SIM) at Department of Management, University of Dhaka, Bangladesh. His was born in 1996 in Khulna, Bangladesh. He has secured first position in Bachelor of Business Administration (BBA) at Department of Management, University of Dhaka with Dean Honor Merit Award in 2019. $\mathrm{He}$ has an excellent academic background and keen interest on regional economic integration, strategic management, and corporate governance. 
Md. Hasan Mia. Md. Hasan Mia is currently pursuing his Masters of Business Administration (MBA) degree in Human Resource Management (HRM) at Department of Management, University of Dhaka, Bangladesh. His was born in 1996 in Dhaka, Bangladesh. He has secured third position in Bachelor of Business Administration (BBA) at Department of Management, University of Dhaka. He has an excellent academic background and keen interest on human capital, human resources, talent management, and information technology.

\section{Appendices}

\section{A Questionnaire on Prospects of Ride-sharing Services in Bangladesh}

SECTION-A: BIOGRAPHICAL INFORMATION

\begin{tabular}{|l|l|l|l|l|}
\hline 01. & Your name & \multicolumn{2}{|l|}{} \\
\hline 02. & Gender & $\square$ Male & $\square$ Female & $\square$ Above 40 \\
\hline 03. & Your age & $\square$ Below 30 years & $\square 30$ years-40 years & $\square$ Others \\
\hline 04. & $\begin{array}{l}\text { Your } \\
\text { profession }\end{array}$ & $\square$ Student & $\square$ Business & $\square$. \\
\hline
\end{tabular}

\section{SECTION-B: JUDGING PROSPECTS OF RIDE SHARING SERVICES}

05. Have you ever used ride-sharing services?

\section{Yes} No
06. If your answer is $\mathrm{NO}$, then which factors persuade you not to using it?

it in a month?

07. If your answer is YES, then how frequently do you use

\begin{tabular}{|l|l|}
\hline & Lack of trust \\
\hline & Unprofessionalism \\
\hline & Lack of reliability \\
\hline & No access to internet \\
\hline & $\begin{array}{l}\text { Lack of knowledge regarding ride- } \\
\text { sharing apps }\end{array}$ \\
\hline & Security concern \\
\hline & Expensive \\
\hline
\end{tabular}

\begin{tabular}{|l|l|l|}
\hline \multirow{4}{*}{08. And which factors induce you to use it? } & & More convenient \\
\cline { 2 - 3 } & & Real-time response \\
\cline { 2 - 3 } & & Reasonable cost \\
\cline { 2 - 3 } & & User-friendly \\
\cline { 2 - 3 } & & Time-saving \\
\cline { 2 - 3 } & & No maintenance of hassles \\
\cline { 2 - 3 } & & Unique \& luxury feelings \\
\cline { 2 - 3 } & Safe \\
\cline { 2 - 3 } & & On-demand location \\
\cline { 2 - 3 } & & More comfortable \\
\cline { 2 - 3 } & & And others \\
\hline
\end{tabular}




\begin{tabular}{|l|l|l|}
\hline \multirow{4}{*}{09. The Service provider you have used often- } & & Ubar \\
\cline { 2 - 3 } & & Pathao \\
\cline { 2 - 3 } & & Shohoz ride \\
\cline { 2 - 3 } & & Obhai \\
\cline { 2 - 3 } & & Obon \\
\cline { 2 - 3 } & & Gaiwala \\
\cline { 2 - 3 } & Texiwala \\
\cline { 2 - 3 } & others \\
\hline
\end{tabular}

10. Troublesome and problem you usually faced using ride-sharing services-

\begin{tabular}{|c|}
\hline Unexpected delay \\
\hline $\begin{array}{l}\text { Inconsistency of pre-ride and post-ride } \\
\text { fare showed in apps. }\end{array}$ \\
\hline Fraudulent demand for fare \\
\hline Unprofessionalism of driver \\
\hline Rough behavior of the driver \\
\hline Unexpected Accident \\
\hline Personal harassment \\
\hline Non-response on emergency situation \\
\hline Network and internet delay \\
\hline Weak and troublesome apps and serve \\
\hline Unregistered car and bike \\
\hline No Passenger helmets \\
\hline Nonfamiliarity of location of drivers \\
\hline Unfit vehicles \\
\hline $\begin{array}{l}\text { Reluctance to drivers not to provide } \\
\text { desired services. }\end{array}$ \\
\hline Others \\
\hline
\end{tabular}

11. Which types of risk you perceive to use ride-sharing services?

Security

Abuse of personal information

Physical harassment

Prone to Accident

And others

\begin{tabular}{|l|l|l|}
\hline \multirow{4}{*}{$\begin{array}{l}\text { 12. Which improvements do you like to suggest to add value in ride- } \\
\text { sharing services? }\end{array}$} & $\begin{array}{l}\text { Increasing professional skills and } \\
\text { knowledge of drivers }\end{array}$ \\
\cline { 2 - 3 } & \begin{tabular}{l} 
Added simplicity in apps \\
\cline { 2 - 3 }
\end{tabular} & $\begin{array}{l}\text { Strong server and network } \\
\text { More distance coverage }\end{array}$ \\
\cline { 2 - 3 } & $\begin{array}{l}\text { Reduction of price } \\
\text { Increasing service quality } \\
\text { compliance of customer feedback and }\end{array}$ \\
\cline { 2 - 3 } & \begin{tabular}{l} 
Instant compliance handling \\
\cline { 2 - 3 }
\end{tabular} & \begin{tabular}{l} 
Increasing number of workforces \\
\cline { 2 - 3 }
\end{tabular} \\
\hline
\end{tabular}




\section{A Ouestionnaire on Prospects and Challenges of Ride-sharing Services in Bangladesh}

\begin{tabular}{|c|l|l|l|}
\hline 01. & Your name & \multicolumn{2}{|l|}{} \\
\hline 02. & Organization Name & $\square$ Male & $\square$ Female \\
\hline 03. & Gender & & \\
\hline 04. & Designation & & \\
\hline 05. & Work Experience & & \\
\hline
\end{tabular}

\begin{tabular}{|l|l|l|}
\hline \multirow{4}{*}{$\begin{array}{l}\text { 06. The challenges ride-sharing businesses face } \\
\text { nowadays- }\end{array}$} & & Fund Shortage \\
\cline { 2 - 3 } & & Lack of government support \\
\cline { 2 - 3 } & & Inefficiency and unprofessionalism of the workforce \\
\cline { 2 - 3 } & & Lack of awareness of people \\
\cline { 2 - 3 } & & Slow network and internet \\
\cline { 2 - 3 } & & Bureaucratic red tape \\
\cline { 2 - 3 } & & Intense competition \\
\cline { 2 - 3 } & & Absence of economies of scale \\
\cline { 2 - 3 } & Lack of proper logistic support \\
\cline { 2 - 3 } & Difficulties in getting license and route permission \\
\cline { 2 - 3 } & Proper management of information of customers \\
\cline { 2 - 3 } & Immediate compliance and grievance handling \\
\hline
\end{tabular}

07. Do you think the recently imposed $5 \%$ tax will increase the current fare/prices?

08. Which factors do you think are most responsible for not expanding the services in other than Dhaka city?

08. What is the future plan of your organization to reach better and quality services for the well being of the customers?

09. The role should need to be adopted by the government to sustain and flourish the prospects of ride-sharing services? 